BENTHAM OPEN
CrossMark
Content list available at: www.benthamopen.com/TOMEJ/
DOI: $10.2174 / 1874155 \mathrm{X} 01812010081$

REVIEW ARTICLE

\title{
Design and Development of Power Transmission System for Green and Light Weight Vehicles: $A$ Review
}

\author{
Hailemariam N. Hailu* and Daniel T. Redda \\ Mechanical and Industrial Engineering, Addis Ababa University, Addis Ababa, Ethiopia
}

Received: January 01, 2018

Revised: March 19, 2018

Accepted: March 03, 2018

\begin{abstract}
A study on green vehicle was introduced and promoted to minimize the problem of air pollution caused by emissions of conventional vehicle. Green mobility are vehicles with low fuel/energy consumption and low/zero exhaust gas emission, these vehicles are like hybrid, battery powered, and fuel cell electric vehicle that can be enhanced to be more efficient than the conventional vehicles through a new design and development of power transmission system. Power transmission system for green and lightweight vehicles consists of different components like gear box, propeller shaft, differential and final drive. In this review more emphasis is given to gear box due to some reasons: firstly, it is one of the heaviest component of the power train system and as a result weight reduction is critically needed to increase the efficiency of the vehicle. Secondly, gearshift takes place therefore, torque interruption needs to minimize. The use of simulation software's i. e. Mat lab, AMEsim, cruise software and other similar programs can simulate high-efficiency power transmission system. The results from the simulation software will be validated by experimental tests on test rigs. One way of minimizing fuel consumption is to reduce the weight of the gearbox by $10 \%$ reduction in vehicle weight can improved fuel economy by about 5-7\%. As different researchers confirm that to have high vehicle efficiency the type of the transmission they used matters. A vehicle using automated manual transmission (AMT) and dual clutch transmission is more efficient in terms of less energy loss and gearshift comfort.
\end{abstract}

Keywords: Green vehicle, Light weight, Gearshift, Fuel consumption, Power transmission, Clutch.

\section{INTRODUCTION}

Global, regional and local governments are investing heavily in the development of green vehicles like pure electric and hybrid vehicle. Private and government sectors all over the world are searching for technological innovations that reduce costs and increase environment-friendly, and low fuel consumption vehicles [1 - 3]. Due to automobile exhaust that causes air pollution and global warming, electric vehicle (EV)/Green vehicle continues to evolve in a more passionate way to meet the demand for green air. Improving the efficiency and the reliability of these vehicles is a key issue for developing the EV powertrain $[4,5]$.

Discussions on climate change have been posing automotive industry challenges, as carmakers have to meet tight emission standards from different countries. The European Commission established through Regulations 443/2009 and 510/2011 the goal of limiting 130 grams $/ \mathrm{km}$ of C02 emissions from 2006 to 2012 for new passenger cars will reduce CO2 emission level about 25\% [6]. This trend also exists in other countries like Brazil, for one which through

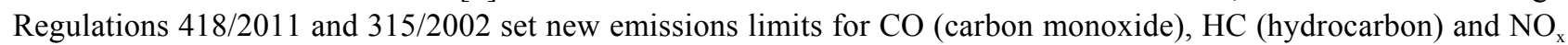
(nitric/nitrogen oxides) [7]. According to Steinberg [8], the cost of reducing each gram of $\mathrm{CO}_{2} / \mathrm{km}$ has already risen from $\$ 17.03(€ 13)$ to $\$ 65.50(€ 50)$ before the 2020 target of $159 \mathrm{~g}$ of $\mathrm{CO}_{2} / \mathrm{km}$ has even been reached [9].

Adapting green technologies will have the potential of reducing C02 emissions by 35 million to 44 million tons from vehicles with IC engine. The cost and green benefit is an optimal solution for technology to improve the fuel efficiency of power transmission by lowering efficiency loss and decreasing drag torque losses in the transmission [10].

\footnotetext{
* Address correspondence to this author at the Mechanical and Industrial Engineering, Addis Ababa University, Addis Ababa, Ethiopia;
} Tel: +251911303439; E-mail: hailuqua@gmail.com 
Automobile technology has brought advancement and convenience to modem lives, but at the same time lead to serious environmental issues. A countermeasure has evolved to address against such problems, an automotive technology such as high-efficiency engine, hybridization, or weight reduction has emerged. Among them, one of the research areas that can provide the most prominent improvements regarding the fuel efficiency and thus emission is the transmission technologies $[11,12]$.

In automotive technology, the term power transmission refers to the group of components that uses to transfer power from the engine and deliver it to the road surface, water, or air [13]. The transmission operation is to reduce higher engine RPM to a slower wheel speed which will increase torque output of the engine. The original type of transmission is Manual Transmission (MT), its basic function is to transfer the engine torque to the vehicle with the desired ratio smoothly and efficiently which needs a driver to operate it. The automotive manufacturer has been developing new technologies for power transmission system such as automatic transmission (AT), continuously variable transmission (CVT), dual clutch transmission (DCT), automated manual transmission (AMT), and electrically variable transmission (EVT) to reduce vehicle fuel consumption and tailpipe emissions [14].

The amount of torque energy wasted on an automatic transmission (AT) is due to its slipping nature of the torque converter applied in the widely-used planetary gear-type or continuously variable automatic transmissions. This disadvantage no longer exists when it comes to the manual transmission (MT), in which the engine and the wheels can be mechanically linked by the clutch. However, manual transmissions require the drivers to skillfully operate the clutch pedal and switch the gear selector, and most drivers find such tasks a challenge. Operating principles that exist in the automatic and manual transmissions led to the development of automated manual transmission (AMT). The AMT enables physical engagement of the engine and wheels through the use of clutch that is automatically controlled using electromagnetic or hydraulic actuators [15].

These days, a couple of efforts have been done to invent novel transmission systems for various types of vehicles [4, 16 - 19].With the present development of transferring power from the engine to the drive wheel, a dual clutch transmission (DCT) has evolved as an innovative and useful technology to solve the issues driving inconvenience or low fuel efficiency of the conventional manual or automatic transmissions for ground vehicles. This emerging technology has the potential to improve the fuel efficiency, reinforce the gear shift performance, and maintain the convenience of the automatic transmission simultaneously. Such benefits can be obtained by using two clutches that engage alternately during the gear shifts to give efficient and seamless torque transmission [20]. Dual clutch transmissions (DCT) resolve such known issues of AT and MT transmissions and emerged as a promising vehicular technology along with other state-of-the-art transmission technologies. [4, 18, 19].

To date, electric vehicles (EVs) have employed single speed reduction gears for transmission [21, 22]. However, to meet the required vehicle performance, such as the acceleration performance, the climbing performance and the maximum speed, with a single-speed reduction gear, a traction motor with a high power and a high $\square$ torque capacity is needed, as well as a high-capacity inverter to drive the motor [23, 24]. Furthermore, a single speed EV has the disadvantage of a relatively low driving efficiency at a high speed because the motor efficiency is relatively low in the high-speed region [23 - 25]. Most small EVs (such as Honda EV [26], Reva [27], etc.) using DC traction motors are equipped with single speed ratio transmission $[13,27,28]$, it may appear that transmissions with multi-speed ratios are unnecessary for EVs.

Expecting to improve the EV performance, researchers and designers are investing much of their resources to the application of multiple speed transmissions instead of traditional single speed transmissions. The detail advantages of two-speed transmission over single speed are demonstrated and reported work [29].

The comparison between IC engine and EV in terms of torque and speed, IC engine is not capable of propelling a vehicle from rest on its own on account of generating low torques at low rpm, a torque amplifying transmission system is very much required, For such vehicles, transmission is also required to allow a vehicle to stop by disconnecting the drive and change the speed ratio between engine and wheels whenever required. On the other hand, this is not the case for an electric vehicle powered by electric motor, since the motor inherently generates a high torque at rest conditions and low rpms, and also delivers maximum power over a wide range of speed as shown in Fig. (1). 


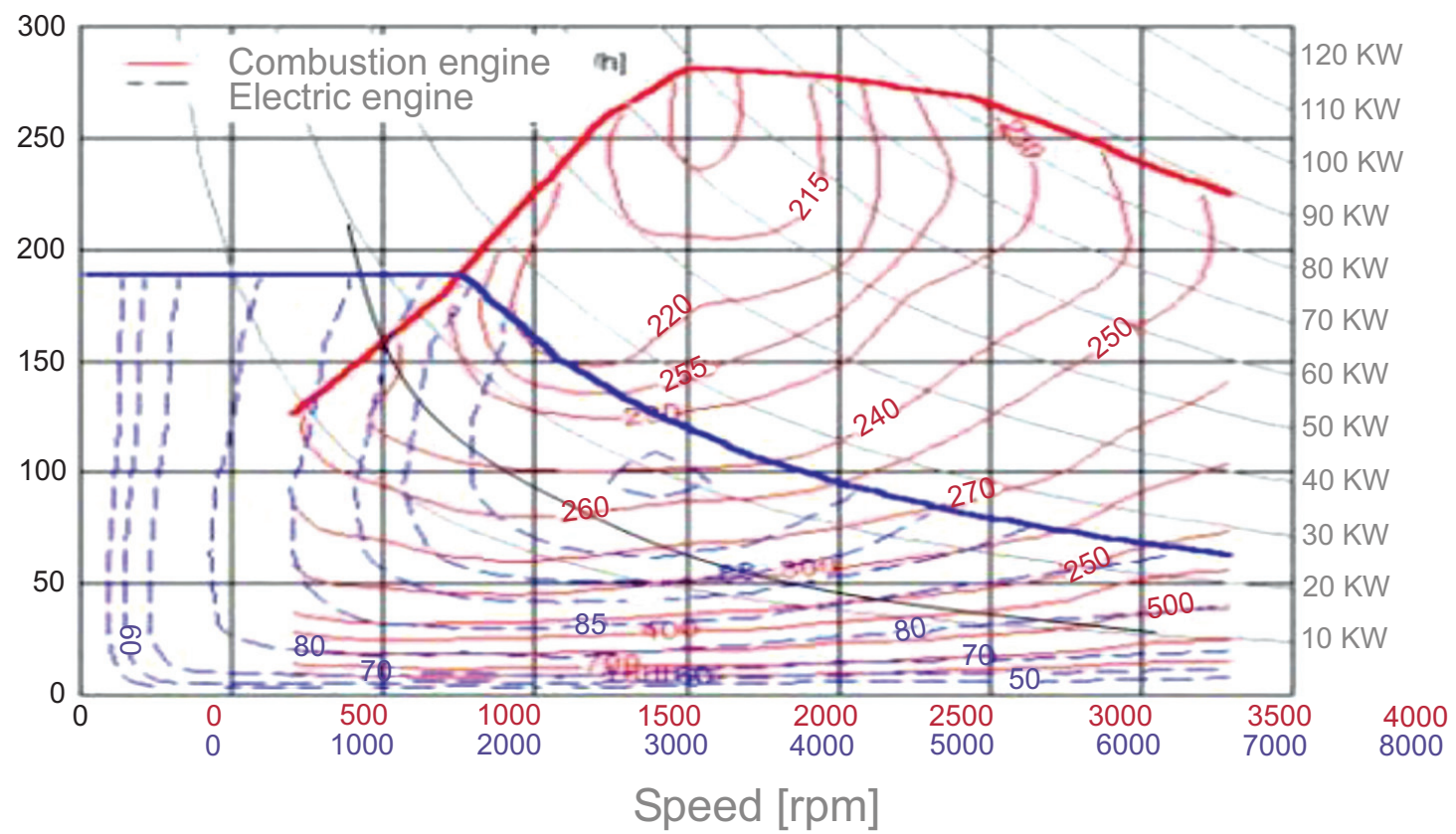

Fig. (1). Comparison b/n EV and IC Engine [30].

\section{METHODS AND MATERIALS USED}

\subsection{Method and Experimental Setup Used}

In order to get the target, showing the methods, how to develop the power transmission system for green and lightweight vehicle, is very crucial. The recent methodology used for Developing of power transmission system for green vehicles in comparison with conventional vehicle. These days the design and methodology of power transmission system can enhance both in terms of efficiency increment and weight reduction. The selection of new power transmission configuration (architecture) for green and lightweight vehicle is very accurate and feasible in terms of design evaluation over the conventional one. As depicted in Fig. (2) there is a clear comparison in design presses of the new automated with conventional.

Conventional Manual Design Process

New Automated Design Process
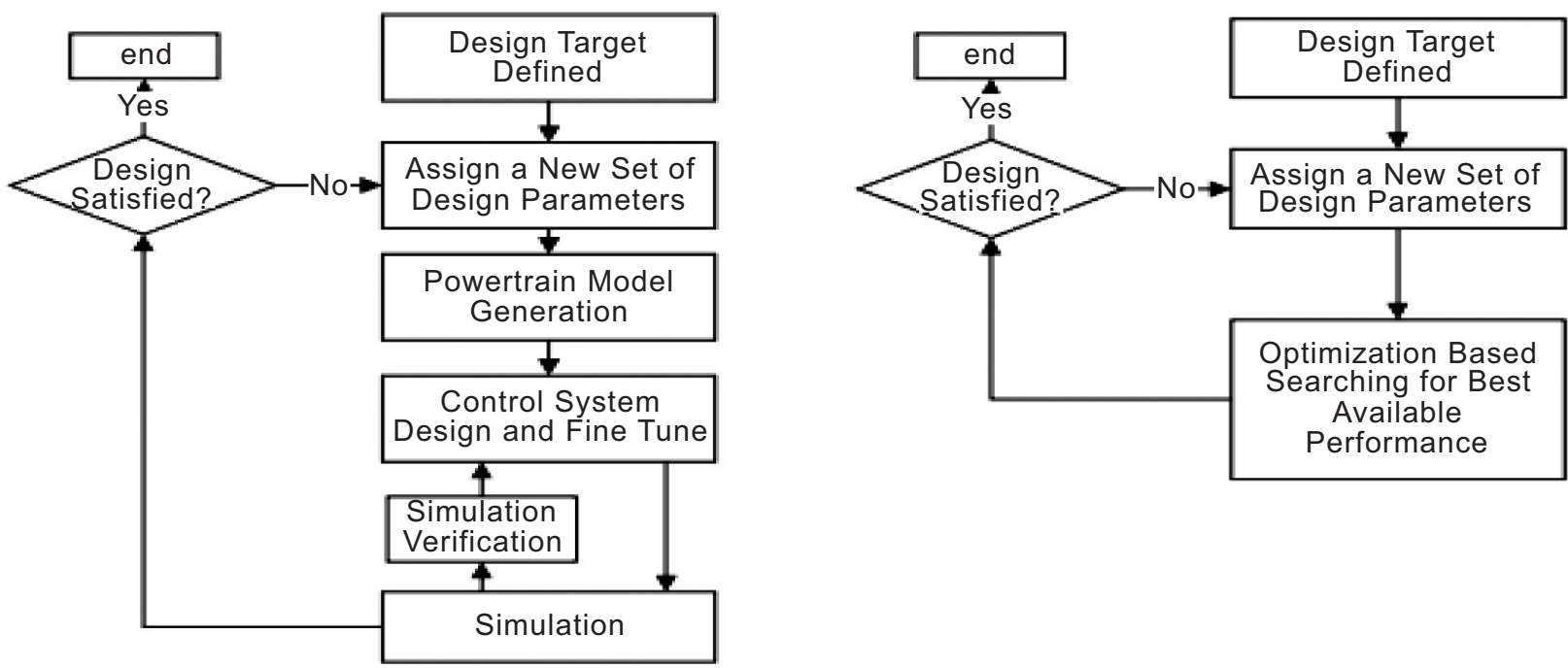

Fig. (2). Schematic of Powertrain Design process Conventional vs. Optimized Approach [31]. 
As can be seen in the schematics of Fig. (2), the transmission design target is defined, new design parameter should set (such as rated power, rated torque and speed) and design and control system was verified (shifting control) [32], the simulation with different software i.e Matlab/simulink, AMEsim and Cruise [33], finally the simulation result should be verified with experiment such as vehicle demonstrator, power train test ring as shown Fig. (3) below.
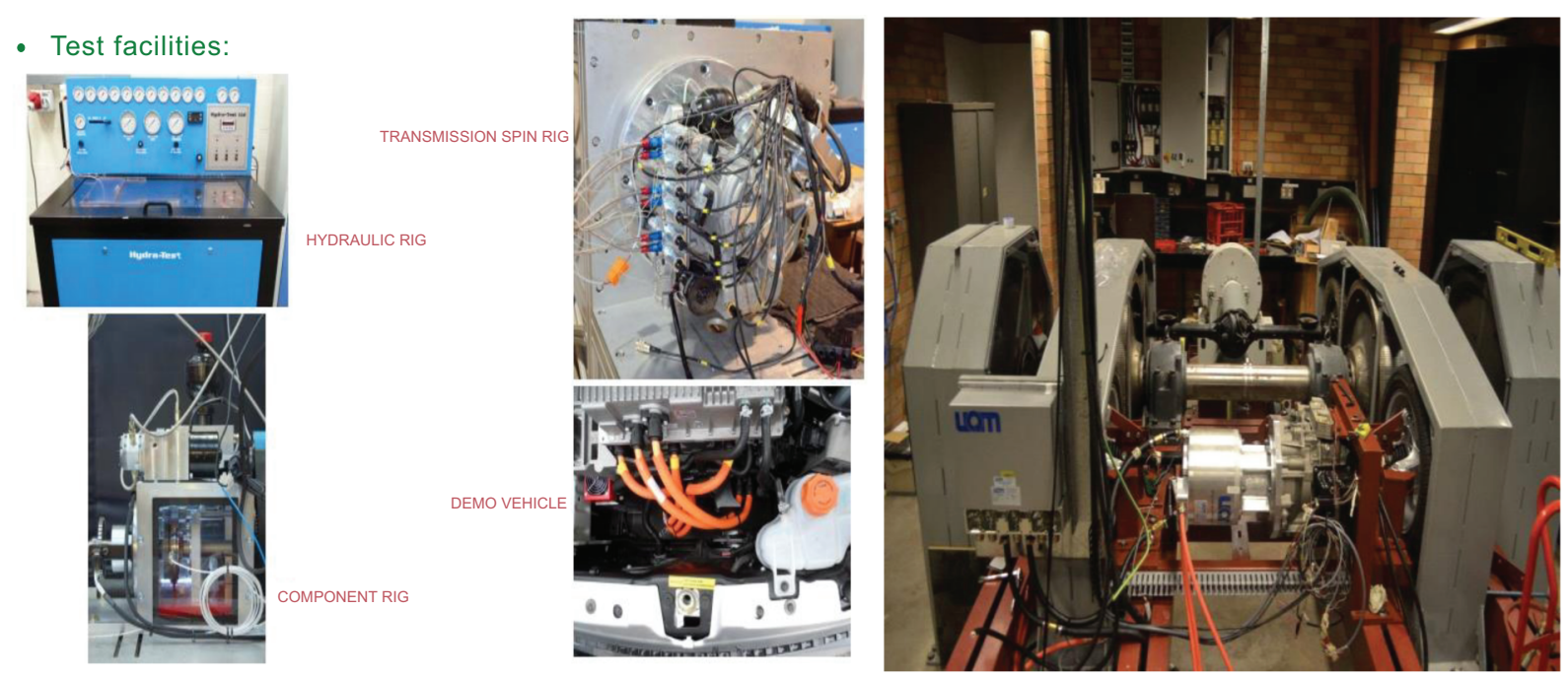

Fig. (3). Experimental Facilities for Transmission System [34].

Zhu, B., et al. [34] discussed about the power train lab of test rig power transmission system components, hydraulic rigs, demo vehicle and driving cycle to test the shifting control and other parameters of .

Design of a new electric vehicle method provides more flexibility to optimize vehicle performance parameters and subsystems like weight, range, drivability, NVH (noise-vibration-harshness), regenerative brake, dedicated

Control algorithms in vehicle control unit etc are shown in Fig. (4) below.

Research paper of $[11,35,38]$, discuss about numerical and experimental investigation of drag torque in a twospeed dual clutch transmission testing performed using a green vehicle powertrain with a two-speed DCT uses a methodology of Measured input and output parameters like speed and torque and oil temperature of DCT case and test rig operated at stable conditions (gear, speed, motor torque, and oil temp) for at least two minutes. Both experiment and simulation were performed accordingly.

\subsection{Material Used for Green vehicle Transmission}

The type of materials used has a significant effect on fuel consumption and weight of vehicles as a result many researchers agree that in every $10 \%$ minimization in vehicle weight can reduce fuel consumption by about $5-7 \%$ so designer and manufacturers spent more time on searching for materials that have lightweight and can withstand the required load [37, 38]. Power transmission system components comprise the heaviest system on the vehicle, therefore, weight reduction is more feasible in terms of fuel consumption [39].

Searching potential materials for power transmission components like gear, shaft, bearing and transmission casing are an essential scenario as material matters the life of transmission components in particular and the vehicle at large. With an anticipated vehicle life of between 10 and 20 years, the material property can increase the life by avoiding any deterioration in mechanical properties while extensive research has been undertaken into aluminum and ultra-high strength steels [40].

To date due to environmental issues researchers are giving focus in composite materials due to good mechanical property. Vehicle power transmission components are manufactured from metal matrix composites (MMCs) that use filaments, whiskers or particles of high strength materials to enhance the properties of the base matrix in critical areas. A more ambitious solution is possible in the medium term, using polymer matrix composites (PMCs) [38]. 


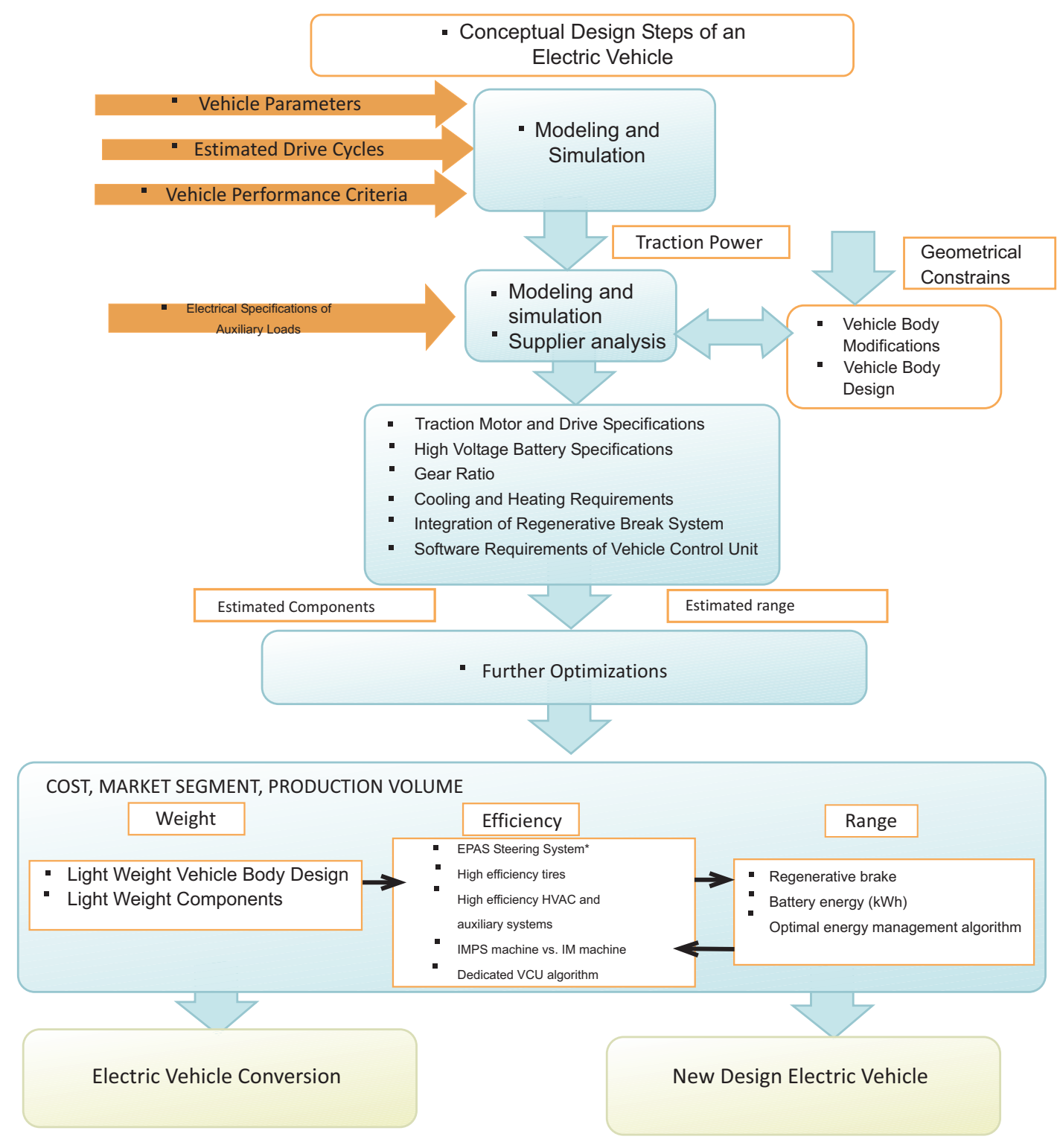

Fig. (4). Design Steps of an Electric Vehicle [32].

The needs for high output, long life, and minimizing the weight of automobiles drive train and machinery are constantly increasing, necessitating further increases in loads to gear and drive system parts like shafts [41]. To meet this demand, further enhancement of the strengths of the individual parts of the vehicle like gears, shafts are required. In response to these demands, a variety of attempts have been made in two aspects such as new material development and process improvement.

The paper of [42] discusses the importance of energy and environmental concerns, in designing transmission components, it is important to pay attention to all aspects of a product including its manufacturing, operation, and maintenance in addition [42] also address that gears are a basic component of vehicle power transmissions. The manufacturing process of transmission gears is, therefore, a central task in the gear production. There is, on one hand, the possibility of giving the tooth contour its final geometry already in the soft state, in which case the gear only need to be hardened. The advantage of this method is the short process chain and results to lower costs. On the other hand, inaccuracies caused by distortion due to hardening are usually unacceptable, in which case hard machining must follow the hardening process. 
Li et al. [43] used pin-on-disc experiments to show that regular steel (16MnCr5) disks on powder metallurgy (PM) material pins, and PM material disks on PM material pins, had lower friction coefficients than regular steel disks on regular steel pins. On the basis of these results [44], investigated the gear mesh torque loss of regular steel gears and PM material gears. They found that running a standard material gear against a PM gear can improve the efficiency of transmission gears. Li et al. also investigated that the gear mesh torque loss of regular steel and PM material ground gears but the efficiency of super finished PM gear are unknown. The current technology shows little potential of gear weight reduction due to the trade-off between mass optimization and the manufacturing process.

Sardinha T G et al. [10] Discusses different materials can be used for the inner and outer part of the gear. In other words, more substantial and more expensive steel is restricted to the outer part which must possess the highest mechanical strength, while the other parts can be manufactured with lower grade steels or alternative steel materials. The process used for hardening the surface is using heat treatment process which can be applied locally.

Research paper of [18] Investigates by applying the technology of Low Pressure Carburizing (LPC) and High Pressure Gas Quenching (HPGQ), the tooth root bending strength can be significantly enhanced, compared to traditional heat treatment with atmospheric carburizing and oil quenching. The hardenability of case hardening steels such as $5130 \mathrm{H}, 5120 \mathrm{H}, 20 \mathrm{MnCr} 5,27 \mathrm{MnCr} 5,18 \mathrm{CrNiMo} 7-6$ etc. has been stepwise increased in recent years. An important factor for fatigue resistance is the grain size after heat treatment. Therefore, grain size control is a key goal when developing new modifications of steel grades. Volker Heuer et al added that after enhancing grain size control, it was possible to increase the carburizing temperatures over the past years from $930^{\circ} \mathrm{C}$ to $980^{\circ} \mathrm{C}\left(1700^{\circ} \mathrm{F}\right.$ to $\left.1800^{\circ} \mathrm{F}\right)$ which resulted in shorter heat treatment cycles and achieve significant cost savings. With the introduction of new micro alloyed steels for grain size stability, carburizing temperatures can now be even further increased to temperatures of up to $1050^{\circ} \mathrm{C}\left(1920^{\circ} \mathrm{F}\right)$, leading to even more economic process cycles. By adding microelements such as Niobium or Titanium in the parts per million (ppm) range, nitride and carbon nitride-precipitates are formed. These precipitates effectively limit the grain-growth during the heat treatment process.

L. ZHANG et al. [45] Discuss about demand for cleaner steels increases every year. In addition to lowering nonmetallic oxide inclusions and controlling their morphology, composition and size distribution, clean steel requires lowering other residual impurity elements such as sulfur, phosphorus, hydrogen, nitrogen and even carbon, and trace elements such as $\mathrm{As}, \mathrm{Sn}, \mathrm{Sb}, \mathrm{Se}, \mathrm{Cu}, \mathrm{Pb}$, and $\mathrm{Bi}$.

Bao et.al [46] discuss In order to achieve composition well-controlled alloy steel for the current studies, high purity electrolytic iron was melted in a vacuum induction furnace, then high purity electrolytic manganese, single crystal silicon chromium-iron, molybdenum-iron and granular carbon powders were added into the crucible to adjust the composition of the steel, and to deoxidize the steel. Aluminum metal was then added to the melt to adjust the content of the dissolved aluminum in the steel. The initially dissolved aluminum in the steel ranged from 14ppm to 503ppm. The steel composition is similar to that of $42 \mathrm{CrMo}$ steel.

Thapliyal, Vivek [47] discussed about the benefits of removing inclusions for outweigh the negatives. Large inclusions can be easily removed from the steel by utilizing good industrial practices. Following are the common techniques utilized to remove inclusions: Degassing treatment, Floatation, Inclusion Entrapment by Slag, Inclusion Entrapment by Refractory, Gas Bubbling and Electromagnetic Stirring

Qi Zhang, et al [48] evaluates contact fatigue strength of the gear; for that motor speed of 1440 RPM was maintained at $1000 \mathrm{Nm}$. Load clutch is carried by front shaft which is used to apply the load. The flanges of the load clutch are twisted relative to each other and bolted together for applying load and torque was applied by weights and load lever.

\section{RESULTS AND DISCUSSION}

The results and discussion of this review papers will discuss in this chapter. Their results are different as they apply different methods and for different applications. Bernd Matthes [20] discuss the fuel efficiency of various power transmission types in terms of fuel saving and comfort rating. As it depicted in Fig. (5) below, the best fuel economy transmission is AMT which is even better than manual transmission. In addition to the AMT, the wet DCTs and dry DCTs have the highest efficiency as well as good comfort. However, if passengers' comfort and driver's preference are considered, AMT is not the first option for conventional vehicles which only contain one power source. Based on the combined factors, the DCTs are the best choice for conventional vehicles. 


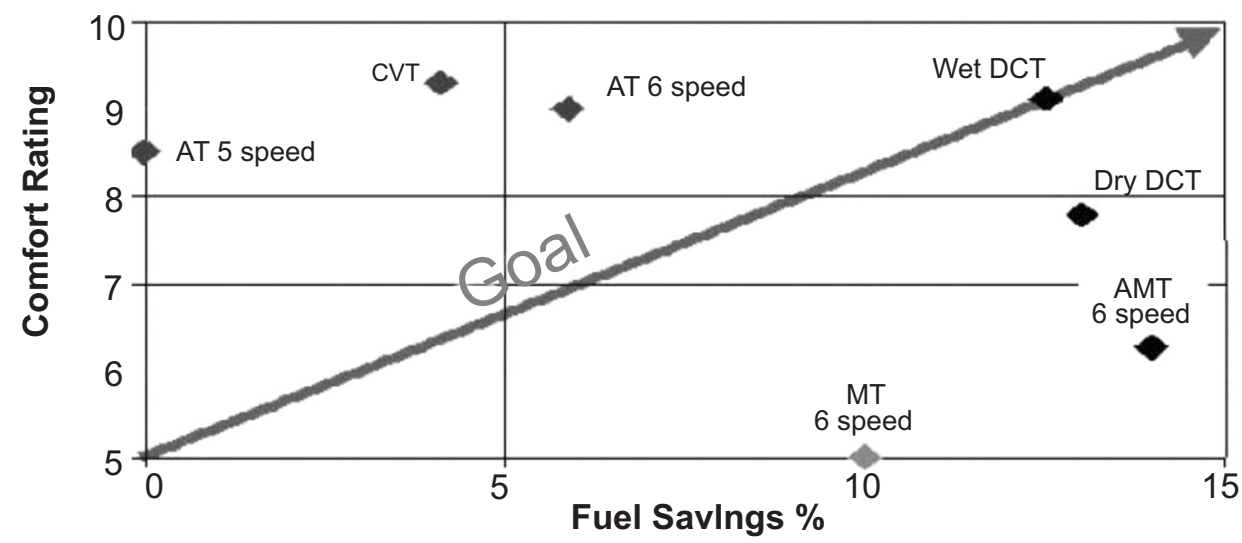

Fig. (5). Transmission Comfort and Fuel Efficiency Comparison [20].

Fig. (6) also shows the efficiency analysis and a comparison between different transmissions types. From the graph as clearly shown that the highest efficiency belongs to DCTs, especially the dry clutch DCT as stated in [49].

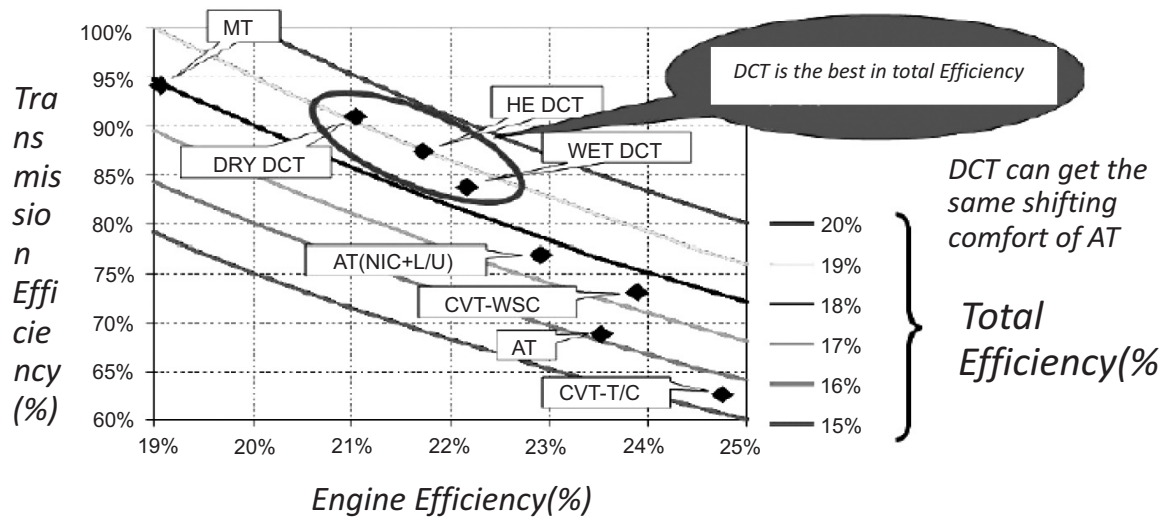

Fig. (6). Transmission Efficiency under NEDC Drive Cycle [49].

Council, N.R [39]. investigated that the difference in power losses between wet and dry clutch DCTs are shown in Fig. (7a) as a result dry DCT has more efficiency than wet DCT. DCTs typically have the lowest losses comparing to other transmission types such as Automatic Transmission (ATs), Dual Clutch Transmission (DCT) and Continues Variable Transmission (CVT) as shown clearly in Fig. (7b).
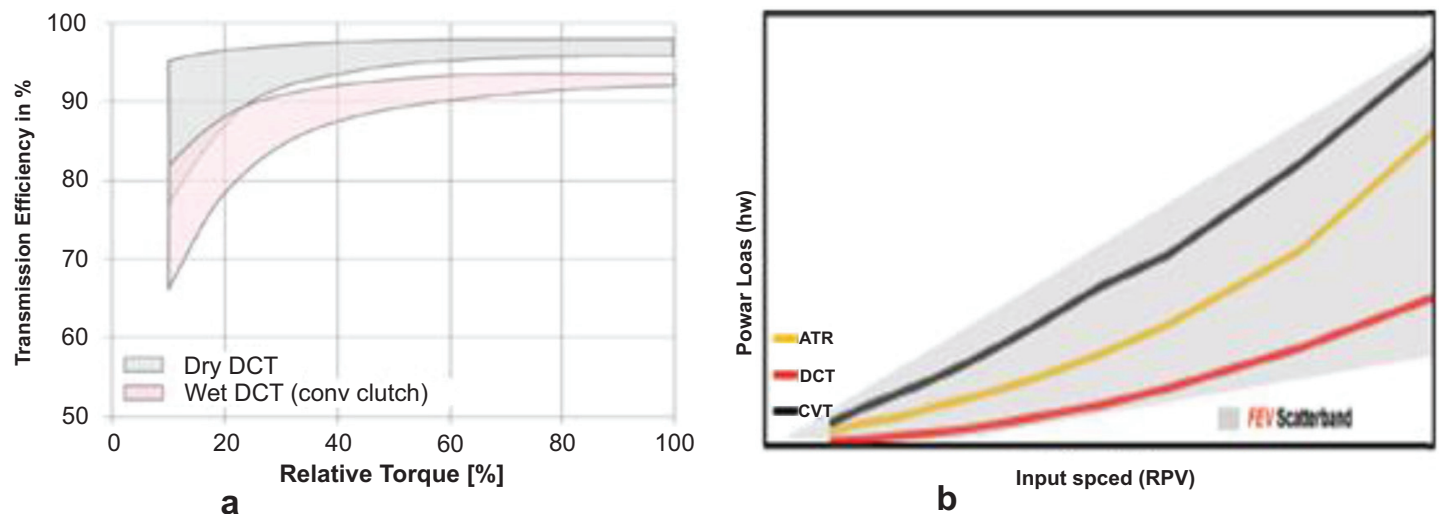

Fig. (7). Comparison of a) Wet and Dry DCT Efficiency b) power losses of d/t transmission [39]. 
Hong, S., et al [36] discuss about the efficiency versus angular speed graph of both experimental and analytical results shows that DCT, average efficiency of about $95 \%$ for both gears although second gear was slightly higher compared to first gear as depicted in the Fig. (8). The results shown in Fig. (8) are the first gear and second gear efficiency both test result and analytical results prediction at constant input torque and constant input speed respectively as depicted in figure below.

(a) $1^{\text {st }}$ gear

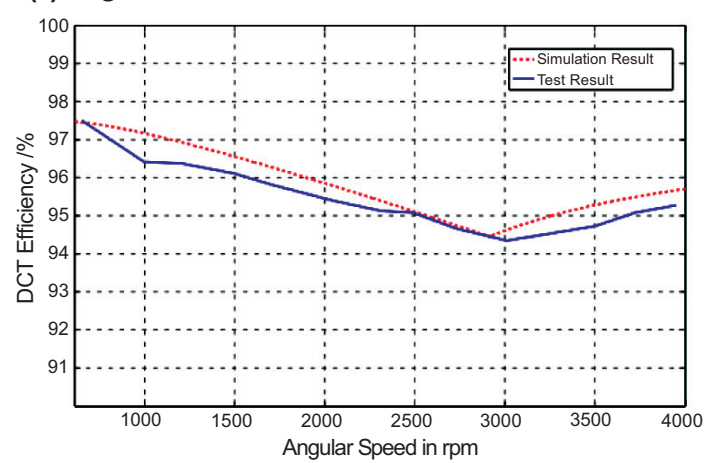

(b) $2^{\text {nd }}$ gear

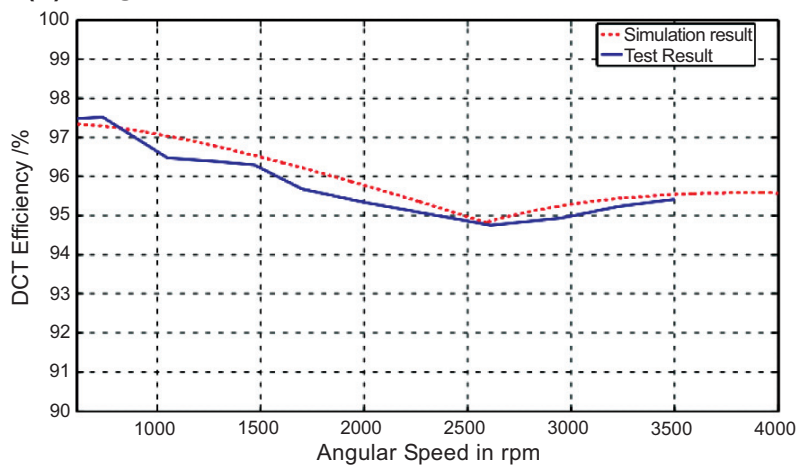

Fig. (8). DCT Efficiency b/n Simulation and Test results with Input Torque $60 \mathrm{~N} \bullet \mathrm{m}[36]$.

In Fig. (9), the graph depicts efficiency versus angular speed with parameters like constant input speed and variable input torque from the power source of electric motor. The input torque for the first gear and second gear is variable while the input speed is constant for both gears. The variable input torque between the two gears is due to variable gear ration i.e. second gear ratio $(G 2=5.36)$ and first one $(G 1=8.45)$.

(a) $1^{\text {st }}$ gear

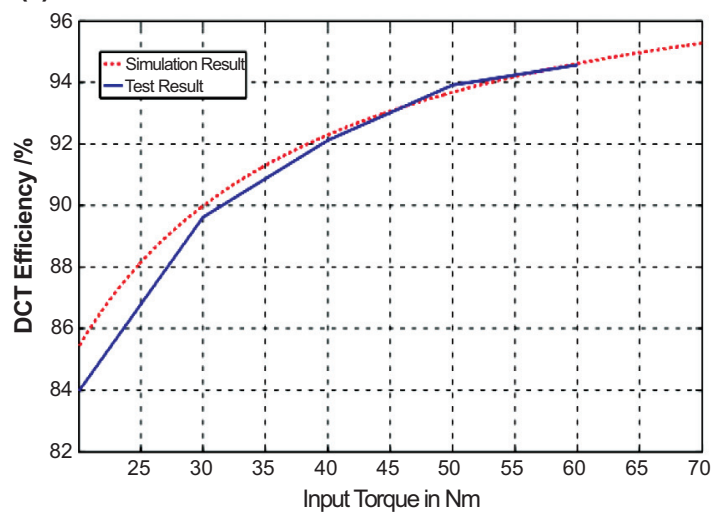

(b) $2^{\text {nd }}$ gear

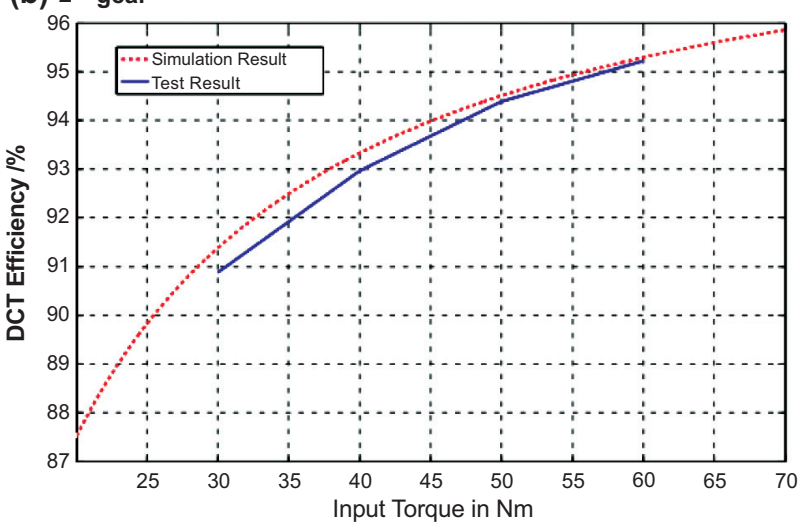

Fig. (9). Comparison of DCT Efficiency b/n Simulation and Test Results with Input speed 3000rpm [36].

Sorniotti, A., et al. [50] discuss the selection of electric drive motor rated speed and maximum speed depends upon the torque-speed characteristics curve of electric motor. As can be seen in Fig. (10), during stating the torque gets higher and the motor speed lower, when the motor speed reaches rated speed the torque decreases as shown clearly in Fig. (10).

Research paper of Sorniotti, A., et al. [50] also discussed about a different type of power transmission system of green vehicle. The comparison study has been done with green vehicles equipped with 2-speed and single speed transmission. As results shown in Fig. (12a \& b), 2-speed transmission have higher torque in the first gear compared to single speed transmission. In addition, the electric motor speed increases in second gear compared to single speed transmission. As results shown in Fig. (12b) 2-speed transmission bring an increase of 34\% in wheel torque compared to single speed transmission, in the same manner the motor speed increases $24 \%$ over single-speed transmission, and 
consequently in a higher efficiency region of the motor drive as shown in Fig. (11) of the efficiency map of electric motor. The advantages of 2- speed transmission can Stall torque requirement can reduce this leading to downsizing of electric machine and the efficiency can be optimized, which leads to increased driving range and Top speed can be increased as shown in Fig. (13) below [53, 54].

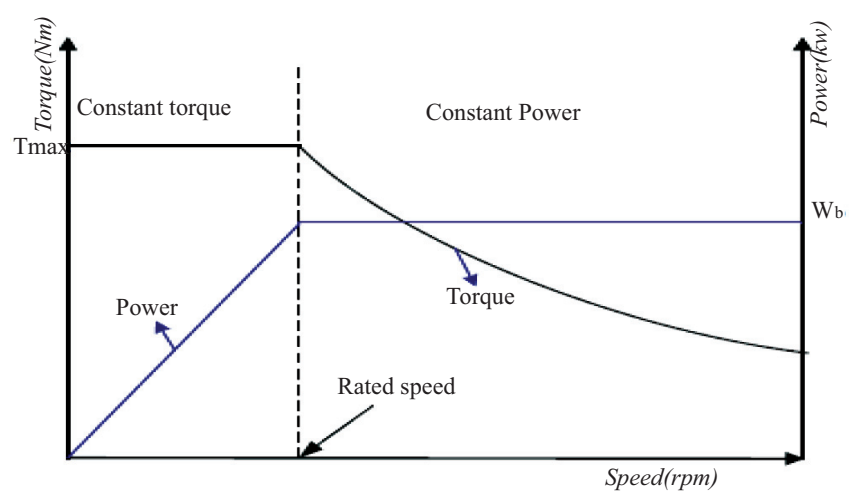

Fig. (10). Drive Motor Torque Characteristics [51].

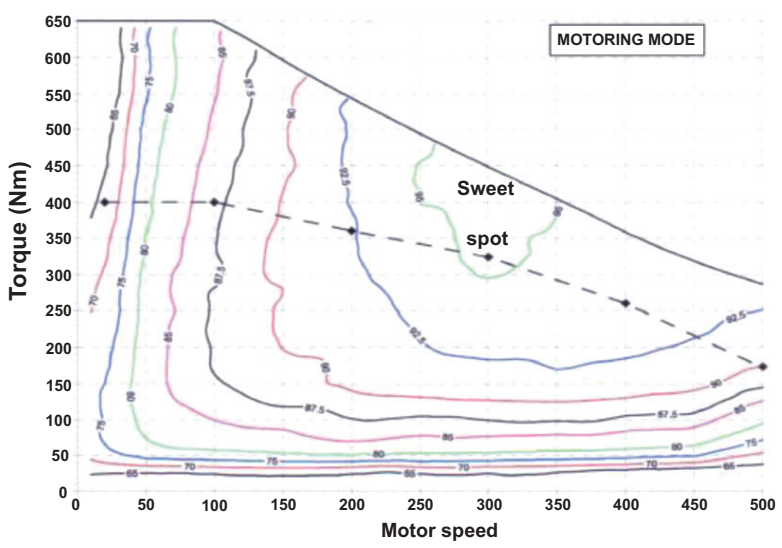

Fig. (11). Efficiency Map of Electric Engine [52].
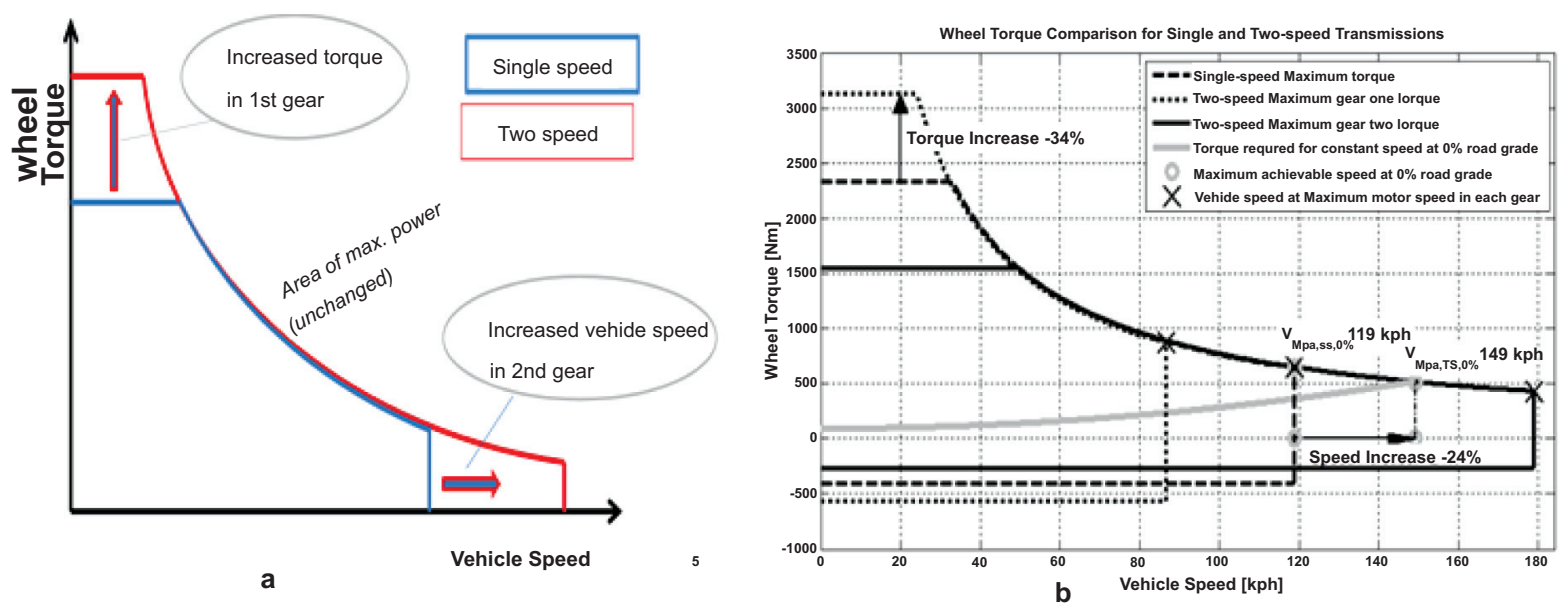

Fig. (12). Advantage of 2 Speed Transmissions over Single Speed Transmission [54].

Sorniotti, A., et al. [50] also discussed the comparison between single speed and 2-speed transmission based on the Optimum efficiency of electric machines typically at medium or high speed and at high load. However, in reality, the 
most frequent use in real driving is at various speeds and at relatively low load. Two speeds transmission can increase the effective area of high efficiency over single speed transmission as shown in Fig. (14) [54].
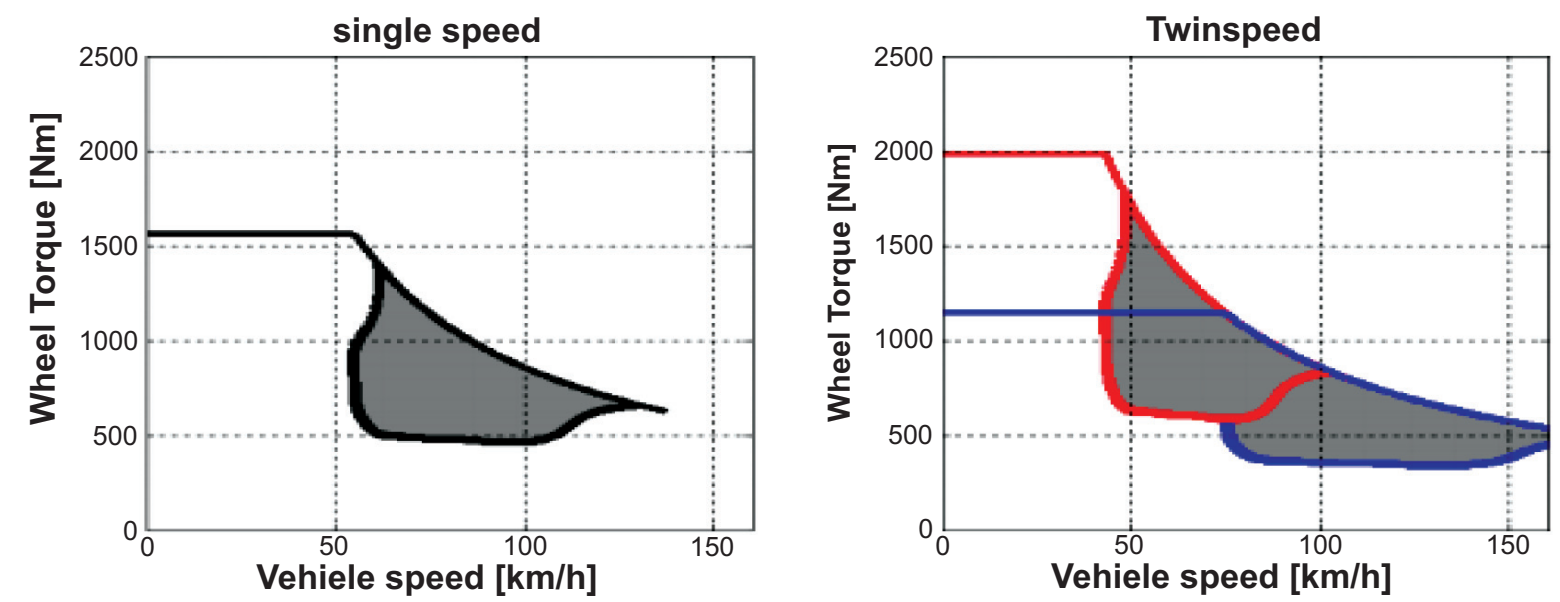

Fig. (13). Comparison of Working is b/n Single Speed \& 2- Speed Transmission [50].

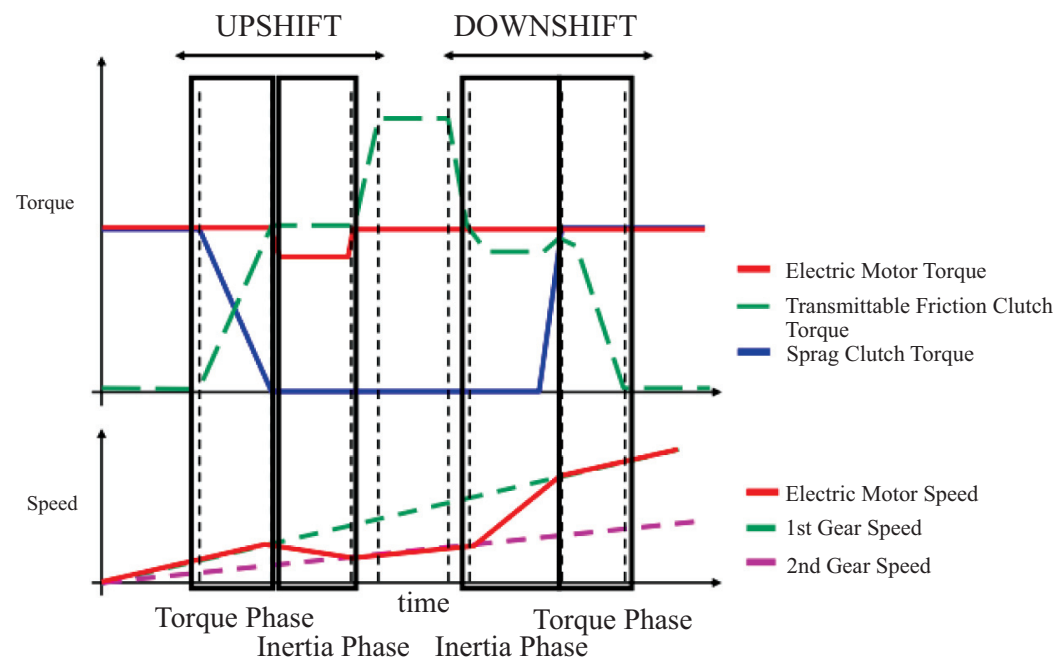

Fig. (14). Upshift and Downshift of 2 Speed Transmissions [36].

Felden, M., et al. [30] discussed the chart in Table 1 below, which illustrates the advantages and disadvantages of the various electric vehicle transmission concepts. As long as one can dispense with the purely cylindrical dimensions of the electric engine, the spur gearbox offers the simpler solution for the coaxial layout. Based on these considerations, a 2-speed gearbox is only possible with a spur gearbox. The spur gearbox is also recommended for parallel coaxial layouts.

Table 1. Comparison of d/t Gearbox for EV [30].

\begin{tabular}{|c|c|c|c|c|c|}
\hline \multirow{2}{*}{$\begin{array}{c}\text { Type/ } \\
\text { layout }\end{array}$} & \multicolumn{2}{|c|}{ Build length } & \multirow{2}{*}{$\begin{array}{c}\text { 2 speed } \\
\text { Feasibility }\end{array}$} & \multirow{2}{*}{ Efficiency } & \\
\cline { 2 - 6 } & Transverse & Axial & & \\
\hline $\begin{array}{c}\text { Planetary } \\
\text { coaxial }\end{array}$ & + & & & & \\
\hline $\begin{array}{c}\text { Spur gearbox } \\
\text { coaxial }\end{array}$ & & & & & \\
\hline $\begin{array}{c}\text { Planetary } \\
\text { parallel }\end{array}$ & + & & & & \\
\hline $\begin{array}{c}\text { Spur gearbox } \\
\text { coaxial }\end{array}$ & & & & & \\
\hline
\end{tabular}


Kulkarni, M., T. Shim, and Y. Zhang [13], discussed gearshifts in a dual-clutch transmission (DCT) are realized by torque transfer from one clutch to another without traction interruption due to the controlled slippage of the clutches. A shift control algorithm to improve the shift quality was proposed for an electric vehicle with a dry-type two-speed dualclutch transmission. To analyze the shift characteristics of the target electric vehicle, dynamic models for the two-speed dual-clutch transmission and the drivetrain were developed. Based on the dynamic models, dynamic equations for the transient shift states were derived, and a shift performance simulator was constructed. From analysis of the transient shift state, it was found that the fluctuations in the driveshaft torque, which cause the shift quality to deteriorate, occurred as a result of the inertia torque. Based on the analytical results, a control algorithm was proposed using traction motor torque control as well as shift actuator stroke control. For traction motor control, a compensation torque was applied during the inertia phase. In that phase, actuator stroke control was performed by considering the torque margin and the kissing point during the torque phase instead of the existing map-based control. To evaluate the performance of the proposed control algorithm, a test bench for the target electric vehicle was developed. From the experimental results, it was found that the variations in the driveshaft torque and in the jerk were reduced by the proposed control algorithm, which thereby provides an improved shift quality as S. Hong et.al [36] stated.

F.Viotto, Oerlikon Drive Systems [53], discussed about novel two-speed transmission system as depicted in Figs. (14 and 15). The component parts like sprag clutch which is located in the second shaft while friction clutch is found in the primary shaft of dual shaft transmission. The principle operation of transmission works as follows, the input torque is transmitted by the sprag clutch whilst in first gear, and by the friction clutch whilst in second gear. The friction clutch is applied to transfer torque from the sprag clutch during an upshift, and released to allow the sprag clutch to engage to accomplish a downshift. Generally, the 2 speed DCT transmission is advantageous in terms of gearshift comfort and fuel efficiency.

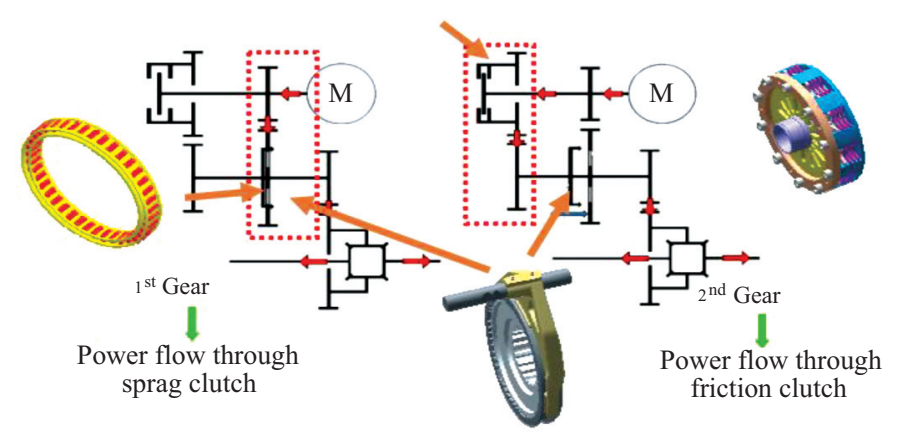

Fig. (15). Schematic Transmission Operation in first gear (left) and second gear (right) [53].

\section{CONCLUSION}

The continuing demand for fuel economy improvements is forcing the automotive industry to reduce weight. The current trend towards lightweight design in automotive industry, also the weight of the transmissions has to be reduced. An optimization of the production process is necessary as well as the reduction of input material. Furthermore, reducing the weight and loss of transmission components can increase fuel efficiency and enhance greenness of vehicle.

To minimize the drag torque the shifting time should minimize. Therefore, decreasing the gearshift time can enhance vehicle comfort this can be done with the help of actuators.

\section{CONSENT FOR PUBLICATION}

Not applicable.

\section{CONFLICT OF INTEREST}

The authors declare no conflict of interest, financial or otherwise.

\section{ACKNOWLEDGEMENTS}

Declared none. 


\section{REFERENCES}

[1] M. Ehsani, Y. Gao, and A. Emadi, Modern electric, hybrid electric, and fuel cell vehicles: fundamentals, theory, and design, CRC press, 2009

[2] M.F.H. Vehicles, Associated press article published in Macomb Daily, 2004.

[3] A. Ebron, and J. Ranta, Education and outreach for future fuels-tapping into cool and addressing resistance the advanced electric drive vehicle education program a program of west virginia university..

[4] J. Shin, J. Kim, J. Choi, and S. Oh, "Design of 2-speed transmission for electric commercial vehicle", Int. J. Automot. Technol., vol. 15, p. $145,2014$.

[http://dx.doi.org/10.1007/s12239-014-0016-8]

[5] Y. Itakura, Osumi Y., and LI G., "One Motor Type Electric Vehicle Drive System", Technical review, 2011.

[6] N. REGULATION, "510/2011 of the European parliament and o the council", May, 11 $1^{\text {th }}, 2011$.

[7] D.F. Brasil, Resolution no. 315, dated October 29, 2002. Provides for the new stage of the Vehicle Emission Control Program-PROCONVE, vol. 20. Daily Official of the Union, 2002.

[8] I. Steinberg, R. Nasdal, and A. Kurtzke, "GETRAG 6HDT451:"Mild-Hybrid Including Wet-Running Dual-Clutch", 35th VDI Congress, Vehicle Transmissions, 2011

[9] H. Naunheimer, B. Bertsche, J. Ryborz, W. Novak, H. Naunheimer, and B. Bertsche, "Matching Engine and Transmission", Automot. Transmission., pp. 115-139, 2011.

[10] J. Savoy, "Light-Weight Assembled Gears: A green design solution for passenger and commercial vehicles", Gear Technology, pp. 64-71, 2013.

[11] J.J. Oh, S.B. Choi, and J. Kim, "Driveline modeling and estimation of individual clutch torque during gear shifts for dual clutch transmission", Mechatronics, vol. 24, pp. 449-463, 2014. [http://dx.doi.org/10.1016/j.mechatronics.2014.04.005]

[12] P.D. Walker, A.R. Salisa, B. Zhu, and N. Zhang, "Modelling and optimisation of pure electric vehicle powertrains: A comparison of single and two speed transmissions", Int. J. Vehicle Perform., vol. 2, pp. 85-102, 2015. [http://dx.doi.org/10.1504/IJVP.2015.074125]

[13] M. Kulkarni, T. Shim, and Y. Zhang, "Shift dynamics and control of dual-clutch transmissions", Mech. Mach. Theory, vol. 42, pp. 168-182, 2007.

[http://dx.doi.org/10.1016/j.mechmachtheory.2006.03.002]

[14] F. Bottiglione, S. De Pinto, G. Mantriota, and A. Sorniotti, "Energy consumption of a battery electric vehicle with infinitely variable transmission", Energies, vol. 7, pp. 8317-8337, 2014. [http://dx.doi.org/10.3390/en7128317]

[15] B. Szimandl, and H. Németh, "Dynamic hybrid model of an electro-pneumatic clutch system", Mechatronics, vol. 23, pp. 21-36, 2013. [http://dx.doi.org/10.1016/j.mechatronics.2012.10.006]

[16] X. Song, C-S. Wu, and Z. Sun, "Design, modeling, and control of a novel automotive transmission clutch actuation system", IEEE/ASME Trans. Mechatron., vol. 17, pp. 582-587, 2012. [http://dx.doi.org/10.1109/TMECH.2011.2176499]

[17] K. Zhao, Y. Liu, X. Huang, R. Yang, and J. Wei, "Uninterrupted shift transmission and its shift characteristics", IEEE/ASME Trans. Mechatron., vol. 19, pp. 374-383, 2014.

[http://dx.doi.org/10.1109/TMECH.2012.2235183]

[18] Y-S. Yoon, S. Kim, and K-S. Kim, "Conceptual design of economic hybrid vehicle system using clutchless geared smart transmission", Int. J. Automot. Technol., vol. 14, pp. 779-784, 2013. [http://dx.doi.org/10.1007/s12239-013-0086-z]

[19] S. Kim, C. Song, K-S. Kim, and Y-S. Yoon, "Analysis of the shifting behavior of a novel clutchless geared smart transmission", Int. J. Automot. Technol., vol. 15, pp. 125-134, 2014. [http://dx.doi.org/10.1007/s12239-014-0014-x]

[20] B. Matthes, Dual clutch transmissions-lessons learned and future potential, 2005. [http://dx.doi.org/10.4271/2005-01-1021]

[21] L. De Novellis, A. Sorniotti, and P. Gruber, "Design and comparison of the handling performance of different electric vehicle layouts", In: Proceedings of the Institution of Mechanical Engineers, Part D: J. Automob. Eng., vol. 228. 2014, pp. $218-232$. [http://dx.doi.org/10.1177/0954407013506569]

[22] A. Sorniotti, S. Subramanyan, A. Turner, C. Cavallino, F. Viotto, and S. Bertolotto, "Selection of the optimal gearbox layout for an electric vehicle", SAE Int. J. Engines, vol. 4, pp. 1267-1280, 2011. [http://dx.doi.org/10.4271/2011-01-0946]

[23] F. Di Nicola, A. Sorniotti, T. Holdstock, F. Viotto, and S. Bertolotto, "Optimization of a multiple-speed transmission for downsizing the motor of a fully electric vehicle", SAE Int. J. Alternative Powertrains, vol. 1, pp. 134-143, 2012. 
[http://dx.doi.org/10.4271/2012-01-0630]

[24] T. Hofman, and C. Dai, "Energy efficiency analysis and comparison of transmission technologies for an electric vehicle", In: Vehicle Power and Propulsion Conference (VPPC), 2010, pp. 1-6. [http://dx.doi.org/10.1109/VPPC.2010.5729082]

[25] Z. Zhang, C. Zuo, W. Hao, Y. Zuo, X. Zhao, and M. Zhang, "Three-speed transmission system for purely electric vehicles", Int. J. Automot. Technol., vol. 14, pp. 773-778, 2013. [http://dx.doi.org/10.1007/s12239-013-0085-0]

[26] C. Xu, J. Niu, and F. Pei, "Design and simulation of the power-train system for an electric vehicle", In: Artificial Intelligence, Management Science and Electronic Commerce (AIMSEC), 2011 2nd International Conference on, 2011, pp. 3868-3871.

[27] C. Xiusheng, S. Yongdao, G. Qiang, and L. Xi, "Shift control for dry dual clutch transmission of pure electric vehicle", In: Transportation, Mechanical, and Electrical Engineering (TMEE), 2011 International Conference on, 2011, pp. 854-857. [http://dx.doi.org/10.1109/TMEE.2011.6199336]

[28] P.D. Walker, N. Zhang, and R. Tamba, "Control of gear shifts in dual clutch transmission powertrains", Mech. Syst. Signal Process., vol. 25, pp. 1923-1936, 2011.

[http://dx.doi.org/10.1016/j.ymssp.2010.08.018]

[29] C. C. Ming, and S. J. Cin, "Performance analysis of EV powertrain system with/without transmission", World Electric Vehicle J., vol. 4, p. 000629 .

[30] M. Felden, P. Bütterling, P. Jeck, L. Eckstein, and K. Hameyer, "Electric vehicle drive trains: From the specification sheet to the drive-train concept", In: Power Electronics and Motion Control Conference (EPE/PEMC), 2010, pp. S11-16. [http://dx.doi.org/10.1109/EPEPEMC.2010.5606531]

[31] E. Schaltz, "Electrical vehicle design and modeling", In: Electric Vehicles-Modelling and Simulations, Ed. InTech 2011. [http://dx.doi.org/10.5772/20271]

[32] M. Karamuk, M.E. Çepni, and S. Otan, "Electric vehicle powertrain development: Conceptual design and implementation", In: International conference on automotive and vehicle technologies, AVTECH: Istanbul, Turkey, 2013.

[33] P.D. Walker, S. Abdul Rahman, B. Zhu, and N. Zhang, "Modelling, simulations, and optimisation of electric vehicles for analysis of transmission ratio selection", Adv. Mech. Eng., vol. 5, p. 340435, 2013.

[http://dx.doi.org/10.1155/2013/340435]

[34] B. Zhu, N. Zhang, P. Walker, W. Zhan, X. Zhou, and J. Ruan, "Two-speed DCT electric powertrain shifting control and rig testing", Adv. Mech. Eng., vol. 5, p. 323917, 2013. [http://dx.doi.org/10.1155/2013/323917]

[35] Y. Liu, D. Qin, H. Jiang, and Y. Zhang, "Shift control strategy and experimental validation for dry dual clutch transmissions", Mech. Mach. Theory, vol. 75, pp. 41-53, 2014. [http://dx.doi.org/10.1016/j.mechmachtheory.2014.01.013]

[36] S. Hong, H. Son, S. Lee, J. Park, K. Kim, and H. Kim, "Shift control of a dry-type two-speed dual-clutch transmission for an electric vehicle", In: Proceedings of the Institution of Mechanical Engineers, Part D: J. Automob. Eng., vol. 230. 2016, pp. $308-321$. [http://dx.doi.org/10.1177/0954407015585686]

[37] I. Stephan, Intelligent lightweight design by forged transmission components. Available from: http://www.massiverleichtbau.de/fileadmin/info/informationen_aus_der_branche/Intelligent_lightweight_design_Hirschvogel_Veroeffentlich ung.pdf

[38] P. Prabhakar, M. Parameshwaran, and S. A. Kumar, Weight reduction of planetary gearbox pedestal using finite element analysis. Available from: http://www.msruas.ac.in/pdf_files/sastechJournals/Sept2013/2_Prabhakar.pdf

[39] N.R. Council, Cost, Effectiveness, and Deployment of Fuel Economy Technologies for Light-Duty Vehicles., National Academies Press, 2015.

[40] J. Kim, K. Cho, and S.B. Choi, "Gear shift control of dual clutch transmissions with a torque rate limitation trajectory", In: American Control Conference (ACC), 2011, pp. 3338-3343.

[41] S. Matsumura, and N. Hamasaka, High Strength and Compactness of Gears by WHSP (Double Hard Shot Peening) Technology. Available from: https://home.komatsu/en/company/tech-innovation/report/pdf/158-03_E.pdf

[42] I.H. Naunheimer, "Specification and Design of Shafts", In: Automotive Transmissions, ed: Springer Berlin, Heidelberg, 2011 , pp. $278-299$. [http://dx.doi.org/10.1007/978-3-642-16214-5_8]

[43] X. Li, M. Sosa, and U. Olofsson, "A pin-on-disc study of the tribology characteristics of sintered versus standard steel gear materials", Wear, vol. 340 , pp. 31-40, 2015. [http://dx.doi.org/10.1016/j.wear.2015.01.032]

[44] X. Li, and U. Olofsson, "FZG gear efficiency and pin-on-disc frictional study of sintered and wrought steel gear materials", Tribol. Lett., vol. 60 , p. 9, 2015. [http://dx.doi.org/10.1007/s11249-015-0582-6]

[45] L. Zhang, B.G. Thomas, X. Wang, and K. Cai, "Evaluation and control of steel cleanliness-review", In: Steelmaking Conference Proceedings, 2002, pp. 431-452. 
[46] S. Bao, X. Wang, L. Zhang, S. Yang, and K. D. Peaslee, Improving steel cleanliness through slag refining, 2008.

[47] V. Thapliyal, Inclusion engineering in Mn-Si de-oxidized steel for thin-strip casting., Missouri University of Science and Technology, 2015.

[48] Q. Zhang, J. Zhang, C. Wu, Z. Xu, and S. Lyu, "The evaluation of contact fatigue strength for 20MnCr5 carburized gear", Int. J. Precis. Eng. Manuf., vol. 15, pp. 117-121, 2014.

[http://dx.doi.org/10.1007/s12541-013-0313-6]

[49] B. Zhu, Research of two speed DCT electric power-train and control system, Doctoral dissertation, 2015.

[50] A. Sorniotti, T. Holdstock, G.L. Pilone, F. Viotto, S. Bertolotto, and M. Everitt, "Analysis and simulation of the gearshift methodology for a novel two-speed transmission system for electric powertrains with a central motor", In: Proceedings of the Institution of Mechanical Engineers, Part D: J. Automob. Eng., vol. 226. 2012, pp. 915-929.

[http://dx.doi.org/10.1177/0954407011431415]

[51] M. Zhou, L. Zhao, Y. Zhang, Z. Gao, and R. Pei, "Pure electric vehicle power-train parameters matching based on vehicle performance", Int. J Contr. Automat., vol. 8, pp. 53-62, 2015. [http://dx.doi.org/10.14257/ijca.2015.8.9.06]

[52] F. Viotto, A novel seamless 2-speed Transmission system for electric Vehicles, Principles and simulation results, 2011.

[53] A. Sorniotti, G.L. Pilone, F. Viotto, S. Bertolotto, M. Everitt, and R. Barnes, "A novel seamless 2-speed transmission system for electric vehicles: Principles and simulation results", SAE Int. J. Engines, vol. 4, pp. 2671-2685, 2011. [http://dx.doi.org/10.4271/2011-37-0022]

[54] K. Hata, T. Imura, and Y. Hori, Dynamic wireless power transfer system for electric vehicle to simplify ground facilities-power control based on vehicle-side information EVS28, 2015.

(C) 2018 Hailu and Redda.

This is an open access article distributed under the terms of the Creative Commons Attribution 4.0 International Public License (CC-BY 4.0), a copy of which is available at: (https:/creativecommons.org/licenses/by/4.0/legalcode). This license permits unrestricted use, distribution, and reproduction in any medium, provided the original author and source are credited. 